\title{
Genetic Mutations in the LTR Region of SRLV Viruses in Capra ibex
}

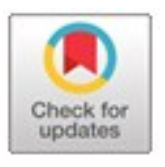

\section{Esadk A. Erhouma}

Microbiology Department, Faculty of Science, Alzintan University, Alzintan - Libya. Research and Scientific Consultations Centre RSCC, Alzintan University - Libya.

Received:30 January 2020/ Accepted: 17 August 2020

Doi: https://doi.org/10.54172/mjsc.v35i2.321

\begin{abstract}
The lentivirus (genus of the retroviruses family) can integrate a significant amount of viral cDNA into the DNA of the host cell and can efficiently infect dividing cells. They are able to spill over from their natural host species to induce new infections and pathologies among hosts of new species. This defines the crossing of species barrier that originates emergent viruses causing emergent diseases. The transmission of lentiviruses was observed between different species (domestic \& wild). The small ruminant lentiviruses (SRLV) transmission is accompanied by genetic mutations in the genome of the virus. In this article, we have studied the genetic mutations that accompany the infection and adaptation of SRLV to the new host. Genetic mutations were studied by amplifying and sequencing the Long Terminal Repeat (LTR) region.Blood samples were taken from Capra ibex living in the French Alps. Sera were tested using a commercially available ELISA. Peripheral blood mononuclear cells (PBMC) isolated on a Ficoll gradient were cultured in a macrophage differentiation medium to obtain monocyte-derived macrophage (MDM) monolayers for virus isolation. DNAs from non-cultured PBMC were used as templates for the PCR amplification of proviral DNA. PCR products (270 nt) were cloned and sequenced. Sequences were analysed using ClustalW.The alignments of the LTR fragment show three types of nucleotide mutations: replacement, addition, and deletion of nucleotide. Sequence analysis shows that the TATA box and the poly (A) site were highly conserved. The divergence of the LTR region between sequences obtained varied by $0.3-5.7 \%$. These differences were also shown by the phylogenetic tree. It can be seen that proviruses from the Capra ibex sequences are a closely related group, quite distinct from the reference sequence.
\end{abstract}

Keywords: Lentivirus; SRLV; LTR; TATA Box; Sequence.

\section{INTRODUCTION}

The lentiviruses - which consist of two major types - are non-oncogenic retroviruses responsible in humans and several species of mammals for slowly progressive diseases: Lentiviruses capable of infecting lymphocytes and some of which can induce immunodeficiency and death of the infected host such as the HIV (Human Immunodeficiency Virus) type 1 and HIV type 2. The second type: Lentiviruses that do not infect lymphocytes and do not induce immunodeficiency but inflammatory or degenerative diseases affecting various organs - after a long latent period- such as the lungs, joints, mammary glands, and the central nervous system such as the small ruminant lentiviruses (SRLV) which cause persistent infections in domestic ruminants and wild small ruminants (Erhouma et al., 2008). The lentiviruses are able to spill over from their natural host species to induce new infections and pathologies among hosts of new species. This defines the crossing of species barrier that originates emergent viruses causing emergent diseases. During these last decades, several emergent lentiviruses were discovered in humans and animals occurring in many parts of the world. The

*Corresponding Author: Esadk A. Erhouma esadk72@yahoo.fr , Microbiology Department, Faculty of science, Azintan University, Azintan - Libya. 
presence of many variants in the viral swarm might facilitate cross-species infections. HIV-2 is almost certainly a human-adapted variant of the simian immunodeficiency virus (SIV) from sooty mangabeys (Hirsch et al., 1989), and HIV-1 may similarly be derived from a chimpanzee SIV (Corbet et al., 2000). Again, the SRLVs emerged after the cross-species transfer of closely related domestic ruminants and wild small ruminants in recent times (Erhouma et al., 2008).

The lentiviral genome is organized from the $5^{\prime}$ to the $3^{\prime}$ end and major protein components are contained in the gag gene (group-specific antigen: responsible for encoding the structural proteins), pol gene (polymerase: encodes the reverse transcriptase, protease, and integrase) and $e n v$ gene (envelope: encodes the virus envelope glycoprotein). These genes are flanked by two non-coding LTR sequences (Long Terminal Repeat). The LTRs (control center for gene expression) - divided into the U3, R, and U5 regions - flank the proviral DNA and provide the signals required for transcription, integration, and polyadenylation of viral RNA (Jaime et al., 2013; Yang et al., 2015).The SRLVs transmission is accompanied by genetic changes (mutations) in the genome of the virus (Blatti-Cardinaux et al., 2016). The rapid evolution of lentiviruses is linked in part to a high frequency of mutations, these genetic mutations allow the virus to adapt within the new host (Rihn et al., 2017).

In this study, to better understand the mechanisms involved in the natural transmission of SRLV in the new species, we characterized the genetic variation in the LTR sequences of SRLVs which emerged after cross-species in Capra ibex.

\section{MATERIALS AND METHODS}

Blood samples were taken from three Capra ibex living in the French Alps. Sera were tested for the presence of specific antibodies against ERLVs, using a commercially available ELISA based on the detection of the recombinant LTR protein. Peripheral blood mononuclear cells (PBMC) isolated on a Ficoll gradient were cultured in a macrophage differentiation medium to obtain monocyte-derived macrophage (MDM) monolayers for virus isolation. Genomic DNA was extracted from $5 \times 10^{6}$ PBMC cells using the DNeasy blood and tissue kits (Quiagen, Courtaboeuf, french) according to the manufacturer's instructions. DNA concentration and quality were determined spectrophotometrically and stocks were stored at $-70^{\circ} \mathrm{c}$ until use. DNAs from non-cultured PBMC were used as templates for PCR amplification of the proviral genome with primer sets chosen in a conserved region of the LTR region sequences from published CAEV-Co (Saltarelli et al., 1990) genomes. PCR products $(270 \mathrm{nt})$ were cloned and sequenced. Sequences were analysed using ClustalW software (Thompson, 1997). The nature of these variations is shown in phylogenetic trees constructed using the program NEIGHBOR (Perriere \& Gouy, 1996) method Neighbor-Joining (NJ) (Saitou \& Nei, 1987), with bootstrap values determined over 1000 iterations (Felsenstein, 2002).

\section{RESULTS}

The alignments of the LTR fragment (corresponding to the U3 and R regions) show a large discrepancy between these two types of viral sequences (Figure 1). The alignments aligned show three types of nucleotide mutations: replacement, addition, and deletion (one or more) of nucleotide. Replacement of nucleotides: GG by $\mathrm{TA}$ at position $5, \mathrm{~T}$ by $\mathrm{A}$ at position $10, \mathrm{~A}$ by $\mathrm{G}$ at position $79, \mathrm{~A}$ by $\mathrm{G}$ at position $88, \mathrm{C}$ by $\mathrm{T}$ at position $107, \mathrm{C}$ by $\mathrm{T}$ at position 115 , $\mathrm{AG}$ by $\mathrm{CA}$ at position $118, \mathrm{C}$ by $\mathrm{T}$ at position 171 and $\mathrm{C}$ by $\mathrm{T}$ at position 133. The second type of mutation was an addition of nucleotides: A at position 23 (all sequences), $\mathrm{T}$ at position 32 (sequence CIa2) and $\mathrm{T}$ at position 139 (all sequences). The third type of mutation was a deletion of nucleotides: T at position 22 (sequences CIa2 \& CIa4), A at position 64 (all sequences) and $\mathrm{C}$ at position 98 (sequence CIa6). 
Examination of the aligned LTR sequences shows that the TATA box (TATAA) and the poly (A) site (AATAAA) in the part $\mathrm{R}$ of the
LTR were highly conserved in all sequences (Figure 1).

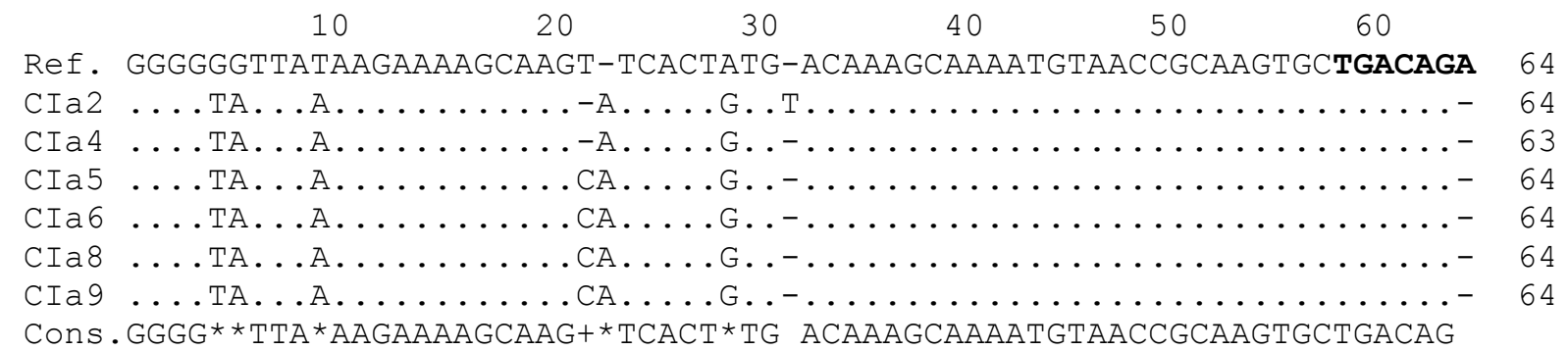

Cons. GGGG**TTA*AAGAAAAGCAAG+*TCACT*TG ACAAAGCAAAATGTAACCGCAAGTGCTGACAG

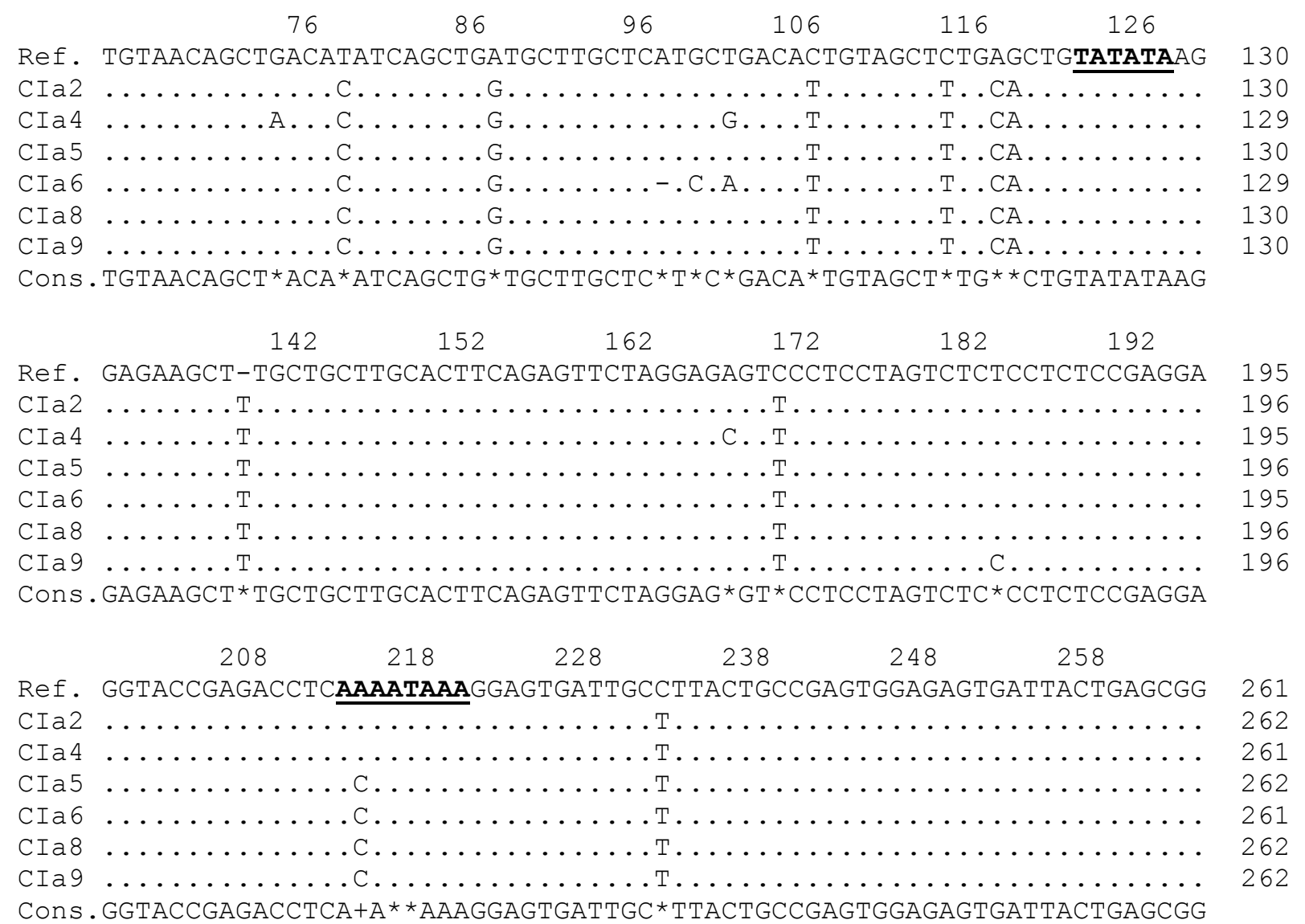

Figure (1): Alignment of nucleotide sequences of the LTR region of the SRLV sequences obtained (Capra ibex: CIa2CIa9) and of SRLV reference strains (CAEV-Co: Ref.). Sequences of the TATA box element (position 124), and the polyadenylation signal (position 214) are within black squares. Sequences of samples with similar scores of mammary lesions are within colored squares. Legend: $(\cdot)$ homology, $(-)$ deletion.

The divergence of the LTR region between sequences obtained (Capra ibex: CIa2-CIa9) and of SRLV reference strains (CAEV-Co: Ref.) varied by $4.7-5.7 \%$. High divergence was observed between sequences $\mathrm{Cla} 7$ and CAEV-Co. The sequence divergence between
CAEV-Co, CIa 8 and CIa9 varied by $5.3 \%$, $5.0 \%$ with that of CIa 5 and by $4.7 \%$ with that of CIa2. The divergence internal between Capra ibex sequences varied by $0.3-1.9 \%$ (Table 1). 
A phylogenetic tree illustrating the relationships between these different LTR sequences was constructed using the neighbor-joining method. It displays proviruses from the Capra ibex sequences (CIa2-CIa9) a closely related group, quite distinct from the reference sequence (CAEV-Co Ref.) (Figure 2).

Table 1: Pairwise nucleotidic genetic distances of the partial LTR region of SRLV reference strain (CAEVCo) and SRLV strains sequenced in this study.

\begin{tabular}{cccccccc}
\hline \hline & Ref & Cla2 & Cla4 & Cla5 & Cla6 & Cla8 & Cla9 \\
\hline Ref. & - & & & & & & \\
Cla2 & 4.7 & - & & & & & \\
Cla4 & 5.4 & 1.3 & - & & & & \\
CIa5 & 5.0 & 0.9 & 1.6 & - & & & \\
Cla6 & 5.7 & 1.6 & 1.9 & 0.9 & - & & \\
CIa8 & 5.3 & 1.3 & 1.9 & 0.3 & 1.3 & - & \\
Cla9 & 5.3 & 1.3 & 1.9 & 0.3 & 1.3 & 0.6 & - \\
\hline \hline
\end{tabular}

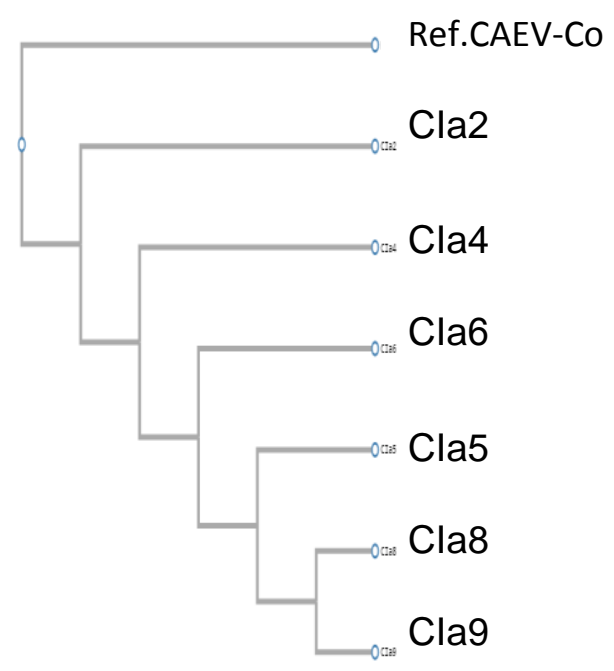

Figure (2): Phylogenetic analysis of the SRLV partial LTR region. Neighbor-joining tree of an approximatively $270 \mathrm{nt}$ fragment from the presently studied sequences. Horizontal lengths are proportional to the estimated genetic distance between the sequences; the bar marker represents a $1 \%$ divergence. Bootstrap values derived from 1000 bootstrap replicates are shown on the phylogenetic tree.

\section{DISCUSSION}

During these last decades, the emergence of several new pathologies in humans and animals has been observed. Many of these emergences have their origin in the crossing of the species barrier by infectious agents. SRLV infection is widespread in most countries of the world (Mendiola et al., 2019). The objective of this study was to analyze the genetic mutations performed by SRLV during infection of Capra ibex. We analyzed approximately 270 nucleotides in the LTR region. The very great homology between the proviral sequences of the LTR region suggests that there has been a passage of SRLV between these species, which is already shown by other studies (Erhouma et al., 2008).

The alignments of the LTR fragment show three types of nucleotide mutations: replacement, addition and the deletion of nucleotide. The sequence analysis shows that the TATA box and the poly (A) site were highly conserved, it is necessary for the virus to maintain these chains of genetic mutations(Mendiola et al., 2019), but the other parties of the LTR may have more mutations (Gayo et al., 2018). Indeed, the regulatory sequences of the genome correspond to non-coding sequences involved in the different stages of the retroviral cycle. The LTR region forms the boundaries between the integrated provirus and the cellular genome. These LTRs are strategic regions of the virus. They include regulatory signals, transcription initiation sites, and signals for integration into the cellular genome.

These terminal regions of the provirus consist of three subdomains U3, R, and U5. The U3 sequence in the $5^{\prime}$ LTR is the most terminal sequence of the provirus in contact with the flanking sequences of the host. The terminal nucleotides of this sequence are part of the att site required for integration. Again, the stability of the TATA box and poly (A) plays an 
important role in viral transcription. The TATA box is used as a site of transcription initiation. Other sites in this region play an important role in viral replication (BlattiCardinaux et al., 2016). These LTR regions are necessary for the integration of the proviral DNA into the genome of the infected cell and are directly involved in the expression of viral genes.

Integration, as the transcription, is a complex and essential step for the expression of viral genes. The ends of the LTRs are cleaved at inverted and repeated (IR) sequences, resulting in the loss of two base pairs at each end of the proviral DNA. The cellular DNA is then cleaved by the viral integrase and then linked to the viral DNA. Finally, viral genes can remain silent for several years or become active in the presence of various cellular stimuli.

\section{CONCLUSION}

The most recent studies show that SRLVs have a very wide tropism since they are capable of infecting the cells of several species of small wild ruminants.

The objective of this work was to study the genetic properties of SRLV following the interspecies passage in ibex to determine the genetic modifications that these viruses have mainly accumulated in the LTR region in order to be able to adapt in these new species. The results obtained reveal an accumulation of numerous molecular alterations in the LTR of isolated SRLVs. This allows a clear answer to the initial question posed, that there are many genetic modifications in the LTR region which accompany the infection and adaptation of viruses in the wild ibex.

\section{ACKNOWLEDGEMENT}

This work was supported by a grant from INRA-France (Action Tranversale Epiemerge) and from the Ministère de l'Environnement (Programme de Recherche Espaces Protégés : Cohabitions et Transmission de Pathogènes).
I'm thankful to the many biologists, veterinarians, and game wardens who helped them to collect samples, and particularly personnel from the "Laboratoire Vétérinaire de Savoie", "Laboratoire Vétérinaire des Hautes Alpes", "Parc National de la Vanoise", "Parc National des Ecrins" and "Office National de la Chasse et de la faune sauvage".

\section{REFERENCES}

Blatti-Cardinaux, L., Sanjosé, L., Zahno, M.L., Zanoni, R., Reina, R., \& Bertoni, G. (2016). Detailed analysis of the promoter activity of an attenuated lentivirus. Journal of general virology, 97(7), 1699-1708.

Corbet, S., Müller-Trutwin, M. C., Versmisse, P., Delarue, S., Ayouba, A., Lewis, J., Brunak, S., Martin, P., Brun-Vezinet, F., \& Simon, F. (2000). env sequences of simian immunodeficiency viruses from chimpanzees in Cameroon are strongly related to those of human immunodeficiency virus group $\mathrm{N}$ from the same geographic area. Journal of virology, 74(1), 529-534.

Erhouma, E., Guiguen, F., Chebloune, Y., Gauthier, D., Lakhal, L. M., Greenland, T., Mornex, J. F., Leroux, C., \& Alogninouwa, T. (2008). Small ruminant lentivirus proviral sequences from wild ibexes in contact with domestic goats. Journal of general virology, 89(6), 1478-1484.

Felsenstein, J. (2002). PHYLIP: Phylogeny Inference Package, ver. 3.6 a3. http:/levolution. gs. washington. edu/phylip. html.

Gayo, E., Cuteri, V., Polledo, L., Rossi, G., García Marín, J. F., \& Preziuso, S. (2018). Genetic Characterization and Phylogenetic Analysis of Small Ruminant Lentiviruses Detected in 
Spanish Assaf Sheep with Different Mammary Lesions. Viruses, 10(6), 315.

Hirsch, V., Olmsted, R., \& Murphy-Corb, M. (1989). Pyrcell and Johnson P. An African primate lentivirus (SIVsm) closely related to HIV-2. Nature, 339, 389-392.

Jaime, M. F. V., Redko, F., Muschietti, L. V., Campos, R. H., Martino, V. S., \& Cavallaro, L. V. (2013). In vitro antiviral activity of plant extracts from Asteraceae medicinal plants. Virology journal, 10(1), 245.

Mendiola, W. P., Tórtora, J. L., Martínez, H. A., García, M. M., Cuevas-Romero, S., Cerriteño, J. L., \& Ramírez, H. (2019). Genotyping based on the LTR region of small ruminant lentiviruses from naturally infected sheep and goats from Mexico. BioMed Research International, 2019.

Perriere, G., \& Gouy, M. (1996). WWWquery: an on-line retrieval system for biological sequence banks. Biochimie, 78(5), 364-369.

Rihn, S. J., Foster, T. L., Busnadiego, I., Aziz, M. A., Hughes, J., Neil, S. J., \& Wilson, S. J. (2017). The envelope gene of transmitted HIV-1 resists a late interferon gamma-induced block. Journal of virology, 91(7).

Saitou, N., \& Nei, M. (1987). The neighborjoining method: a new method for reconstructing phylogenetic trees. Molecular Biology and Evolution, 4(4), 406-425.

Saltarelli, M., Querat, G., Konings, D. A., Vigne, R., \& Clements, J. E. (1990).
Nucleotide sequence and transcriptional analysis of molecular clones of CAEV which generate infectious virus. Virology, 179(1), 347-364.

Thompson, J. (1997). Gibson TJ Plewniak F., Jeanmougin F. and Higgins DG (1997). The ClustalX windows interface: flexible strategies for multiple sequence alignment aided by quality analysis tools. Nucleic Acids Research, 25, 4876-4882.

Yang, F.-C., Kuang, W.-D., Li, C., Sun, W.W., Qu, D., \& Wang, J.-H. (2015). Toll-Interacting Protein Suppresses HIV-1 Long-Terminal-Repeat-Driven Gene Expression and Silences the Post-Integrational Transcription of Viral Proviral DNA. PloS one, 10(4), e0125563. 


\section{الطفرات الوراثية في الموضع الجيني LTR لقيروسات SRLV في الوعول البرية}

\section{الصادق علي رحومـه}

قسم الأحياء الدقيقة . كلية العلوم، الزنتان ـ جامعة الزنتان

مركز البحوث والاستثارات العلمية بجامعة الزنتان.

تاريخ الاستلام: 30 يناير 2020/ تاريخ القبول: 17 أغسطس 2020 https://doi.org/10.54172/mjsc.v35i2.321:Doi

المستخلص: للفيروسات البطيئة Lentivirs (التابعة لعائلة الفيروسات القهرية Retrovirus) القدرة على إدخال، ودمج الحمض

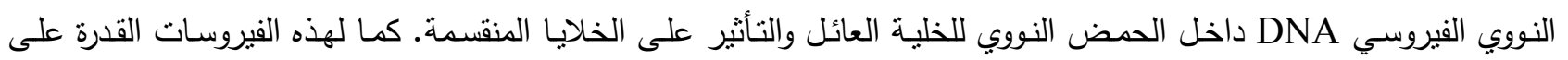
إحداث الإصابة، ونقل الأمراض الجديدة من عوائلها الطبيعية إلى عوائل أخرى جديدة، وذلك ما بطلق عليه عملية "الانتقال بين الأنواع". وتعتبر هذه العملية الأساس لانتقال الفيروسات، ونشر الأمراض الناتجة عنها. لوحظ انتشار الفيروسات البطيئة من جنس الإنس الـ SRLV بين العديد من الأجناس الحيوانية (الأليفة والبرية)، والذي غالبا ما يكون مصحوبا بطفرات وراثية في المادة الوراثية

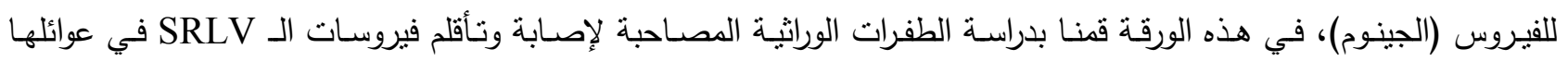
الجديدة. تمت دراسة هذه الطفرات عن طريق مضاعفة الحمض النووي لموضع LTR، وتحليل السلاسل الوراثية المتحصل عليها

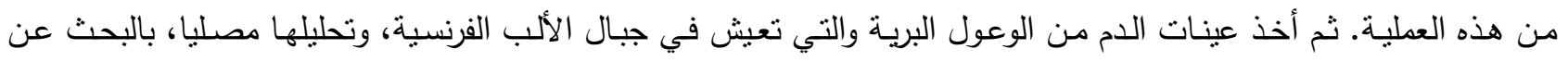

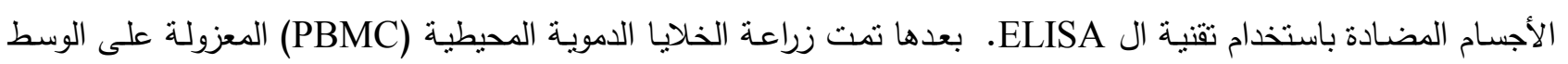

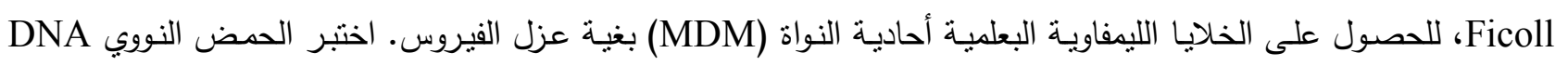
للفيروس المعزول، وتم تحليله باستخدام تقنية الـ PCR باستخدام بادئات من الموضع الجيني المستهدف، للحصول على لــ نسخة

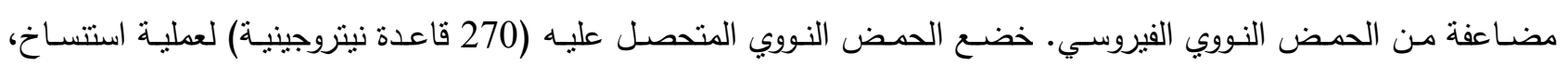

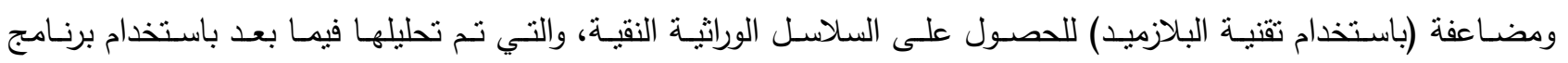

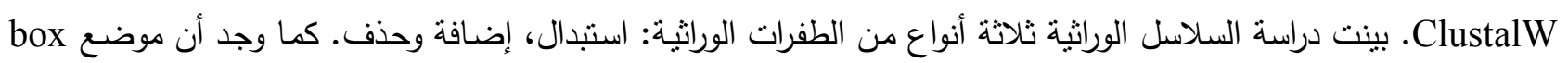
TATA وموضـع عديد الادنين Poly (A) لم تحدث بهما أي طفرات وراثية. معدل الاختلاف بين السلاسل المتحصل عليها

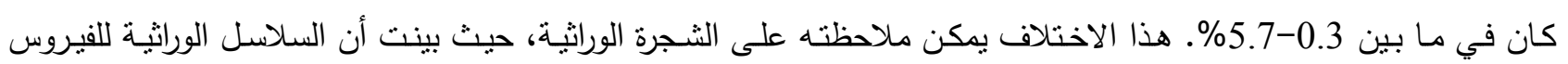
المعزول من الوعول البرية تكون مجموعة مستقلة، وبعيدة عن الفيروس المرجعي. الكلمات المفتاحية: الفيروسات البطيئة، SRLV، LTR، صندوق TATA، تشلسل. 